\title{
Comparative clinical evaluation of safety and efficacy of commonly used drug-eluting stents in coronary artery disease patients after angioplasty in South India: A retro-prospective multi-center study
}

\author{
Vinoth Prabhu Veeramani ${ }^{1 *}$, Saranya P. Selvam ${ }^{2}$, Ahmed Mohsen Hamdan ${ }^{1}$ \\ ${ }^{1}$ Department of Clinical Pharmacy and Pharmacy Practice, Faculty of Pharmacy, University of Tabuk, Tabuk, Kingdom of Saudi Arabia. \\ ${ }^{2}$ Department of Pharmacology, Swamy Vivekanandha College of Pharmacy, Tiruchengode, India.
}

\begin{tabular}{l}
\hline ARTICLE INFO \\
\hline Received on: 29/11/2018 \\
Accepted on: 20/02/2019 \\
Available online: $30 / 03 / 2019$ \\
\\
\hline Key words: \\
Angioplasty, coronary artery \\
disease, drug eluting stents, \\
everolimus, sirolimus, safety \\
and efficacy.
\end{tabular}

\section{INTRODUCTION}

Coronary artery disease (CAD) is the most common form of the heart disease; it typically occurs when there is an imbalance between myocardial oxygen supply and its demand in arteries (Sanchis et al., 2016). Under these circumstances, a person with narrowed coronary arteries will develop angina when exercising. One of the first symptoms of CAD is the appearance of angina when a person is working strenuously (Patel et al., 2010). An estimated 17.9 million people died from cardiovascular diseases (CVDs) in 2016, of these deaths, $85 \%$ are due to heart attack and stroke, $82 \%$ are in low and middle-income countries (WHO,

\section{"Corresponding Author}

Vinoth Prabhu Veeramani, Department of Clinical Pharmacy and Pharmacy Practice, Faculty of Pharmacy, University of Tabuk, Tabuk, Kingdom of Saudi Arabia.E-mail: dr.vinothprabhu@gmail.com
2017). According to the American College of Cardiology (ACC), CVDs accounts for $31 \%$ of all deaths globally, the estimated cost of CVDs will be $\$ 1,044$ billion by 2030 although deaths due to coronary heart disease (CHD) have declined over the past 10 years, CHD remains the leading cause of death in the USA. An estimated 790,000 US adults experience a heart attack each year (Benjamin et al., 2017). The Global Burden of Diseases (GBD) study reported the estimated mortality from CAD in India at 1.6 million in the year 2000, extrapolation of this estimate shows the current burden of CAD in India to be more than 32 million patients (Gupta, 2005). Based on the conservative estimation of epidemiological studies if the current situation continues by the year 2020, the burden of CAD in India will exceed the other countries of the world. CAD is not only the problem in the developed countries. Throughout the world, CAD causes more deaths and disabilities and is 
responsible for more economic costs than any other single illness (WHO, 2017).

Percutaneous coronary intervention (PCI), which was pioneered by Grüntzig in 1977 (Barton et al., 2014) has become the most frequently performed therapeutic procedure in medicine (Nabel and Braunwald, 2012). The stent which was introduced in 1986 was the only innovation that dramatically improved the overall performance of the PCI procedure. Coronary stents improved the procedural safety and efficacy also eliminated the need for surgical standby (Feinberg et al., 2017). But, a major disadvantage in early stents was that the stent-mediated arterial injury elicited neo intimal hyperplasia leading to restenosis and the need for repeat revascularization in up to one third of patients (Li et al., 2009). The subsequent introduction of the drug-eluting stent (DES), which prevented the over-zealous coverage of the stent by tissue, was another significant advance. DESs have been used in clinical practice since 2002 (Pellegrini et al., 2014) and they were developed to specifically address the problems of restenosis encountered with bare metal stents (BMS). The restenosis rate was reduced from $15 \%$ to $3 \%-4 \%$ due to the usage of DESs, it consists of a BMS coated with a polymer which gradually releases a drug to inhibit the cell proliferation that causes restenosis, all the drugs have been released by the polymer for a period of 6-9 months so that the main risk of restenosis has been minimized. DESs with controlled local release of anti-proliferative agents have consistently reduced the risk of repeat revascularization as compared with BMS (Kim et al., 2011; Karjalainen et al., 2011; Stettler et al., 2007). Meanwhile, new platforms for DESs are aimed to improve safety and efficacy. DESs were implanted in more than 500,000 patients in the United States for every year (Sidney et al., 2012).

Second-generation DESs have lots of improvements over the first-generation DESs. Second-generation devices have decreased strut thickness, improved flexibility/ deliverability, enhanced polymer biocompatibility/drug elution profiles, and superior re-endothelialization kinetics. In contemporary practice, second-generation devices are now the predominant coronary stents implanted worldwide (Trevor et al., 2014). When a stent is used and restenosis occurs, this is called in-stent restenosis (ISR). However, a low rate of ISR after DES still exists, and its prevalence is not negligible because of the large population treated with DESs. In spite of the low frequency of ISR events with DESs that contributes the difficulty of the clinical investigation, many studies have addressed the incidence, mechanism, predictors, and optimal treatment of DES restenosis. Recently, mild interactions between some prescribed drugs and DESs were discovered in CAD patients after PCI and termed as drug-drug eluting stent interaction (DDESI) which is defined as interaction between the drug prescribed and drug which is coated on the stent during elution after percutaneous coronary intervention leads to alternations in pharmacokinetic and/ or pharmacodynamics actions of one drug produced by another drug (Veeramani, 2019). Yet, comparative data on safety and efficacy of commonly used DESs are still lacking; therefore, this study was aimed to compare the safety particularly suspected adverse reactions and efficacy of vastly used DESs in South Indian CAD patients in-order to assist the clinicians during decision making to select the appropriate DES for the successful PCI procedures.

\section{METHODS}

\section{Study design and setting}

This retro-prospective multicenter observational study was conducted within some selected hospitals (Vivekanandha Medical Care Hospital, Tiruchengode, Apollo Multi-Speciality Hospital, Trichy, Sri Gokulam Hospital, Salem) from the three different parts of South India. We identified and included patients with CAD who had received PCI with different DES from the beginning of January 2016-2017.

\section{Ethical approval}

This study was approved by the Institutional Ethics Committee for Human Research with the approval number SVCP/IEC/JAN/2016/10 dated 27/01/2016. It is a patients' data collection based observational study; hence, it was exempt from obtaining individual informed consent from each patient according to the ethical standards formulated in the Helsinki Declaration of 1964 revised in 2000, but the purpose and need of this present study was explained to all the participants.

\section{Study population}

We identified a total of $(N=146)$ consecutive CAD patients stented with different DES for this study, that includes i) $N=63$ (54 Male +9 Female) patients with Sirolimus drug-eluting stents (SESs), ii) $N=53$ (40 Male +13 Female) patients with Everolimus drug-eluting stents (EESs) and iii) $N=30$ (24 Male + 6 Female) patients with Zotarolimus drug-eluting stents (ZESs). Sample size was fixed according to the availability of patients as per the following Inclusion criteria, to determine the optimal sample size for this study; the sample size estimation was done using the formula $N=(Z \alpha / 2) 2 \mathrm{~s}^{2} / \mathrm{d}^{2}$, where $s$ is the standard deviation obtained from previous study, and $d$ is the accuracy of estimate. $Z \alpha / 2$ is normal deviate for two-tailed alternative hypothesis at a level of significance. Systematic sampling technique was used in this present study because of its advantages over simple random sampling.

\section{Inclusion criteria}

Nearly, 30- to 64-year-old patients both male and female who underwent angioplasty using at least one DES, with or without complications like hypertension and/or diabetes mellitus and prescribed with or without anti-hypertensive drugs, anti-hyperlipidemic drugs, and/or oral hypoglycemic agents for prospective analysis and patients intervened with any DESs who completed at least 1 year regular clinical follow-up for retrospective analysis were included in this study.

\section{Exclusion criteria}

Patients with age $<30$ and $>64$, pregnancy, lactation, critically ill patients, patients with life style modification alone, 
patients who received only percutaneous transluminal coronary angioplasty without stent implantation, patients who received BMS not DES, patients with complex lesions and who received multiple types of stents concurrently, patients who were diagnosed with acute myocardial infarction [non-ST-elevation myocardial infarction (NSTEMI)] and underwent coronary artery bypass grafting were excluded from this study.

\section{Study protocol}

The patients who met the above inclusion criteria were included in this study and evaluated for the clinical outcomes.

\section{Clinical follow-up}

The clinical follow-up was performed for 3 months once up to 1 year (i.e., at the end of 3rd, 6th, 9th, and 12th month), the information about inpatient clinical outcomes was obtained through review of medical records in hospitals and the longterm clinical outcomes of the discharged patients were collected through telephone follow-up or during their hospital visits for regular checkup.

\section{Clinical endpoints}

The primary end-point of the efficacy was determined by major adverse cardiovascular events (MACE) as well as individual events, which is a composite of cardiac death, target vessel related myocardial infarction (TV-MI), target lesion revascularization (TLR), target vessel revascularization (TVR) and safety was mainly determined by suspected adverse reactions which includes allergic reactions, stent thrombosis (ST), and instent restenosis (ISR) in stent implanted patients. The incidence of adverse reactions also determined during clinical follow-up which was scheduled at the end of $3 \mathrm{rd}$, 6th, 9th, and 12th month after angioplasty.

\section{Statistical analysis}

Statistical analysis was performed using Graph Pad Prism 7 Software and results were expressed as $n(\%)$ or mean \pm standard deviation (SD), column statistics followed by Student- $t$ test were used to analyze the statistical significance, all values under $p<0.05$ were considered as statistically significant.

\section{RESULTS}

\section{Baseline demographic characteristics and clinical presentation of the patients}

The percentage of male population was higher in Group-1 termed as SESs $(85.71 \%)$ then Group-2 ZESs (80\%), but lesser in Group-3 EESs $(77.35 \%)$ patients. The (mean \pm SD) value for age (in years) of EESs $(57.88 \pm 10.42)$ were found to be moderately significant $(p<0.01)$ compared with ZESs $(57.73 \pm 8.17)$ and SESs $(54.29 \pm 9.14)$. The diabetes patients were found to be more in EESs (46.67\%) then SESs (35\%) but ZESs had less significant $(p<0.05)$ diabetes patients $(18.33 \%)$. Similarly most hypertensive patients received EESs (49.20\%) but hypercholestremia patients $(8.9 \%)$ received comparable distribution of all three DESs, respectively, the percentage of smoker and alcoholic were found to be more in SESs population then in EESs and ZESs, many patients with family history of CAD received SESs which are all summarized in Table 1. These results disclosed that SESs were more preferable for males compared with females. Besides, it is highly preferred by most of interventional cardiologists to treat patients with hypertension, hypercholestremia, and family history of CAD.

\section{Baseline cardiac characteristics}

Out of total patients $(N=146)$, maximum number of patients admitted due to Angina pectoris (51.36\%) among all EESs received high percentage $(38.66 \%)$, SESs and ZESs were similar with $30.66 \%$ and considered to be moderately significant $(p<$ $0.01)$. Patients with single vessel disease (SVD) and target vessel disease were high in SESs $(57.69 \%)$ when compared with ZESs $(23.07 \%)$ and EESs (19.23\%), both are considered as significant $(p<0.05)$. Multi-vessel disease (MVD) patients were also high in SESs $(58.97 \%)$ and considered as significant $(p<0.05)$ compared with ZESs (23.07\%) and EESs (15.38\%). Among myocardial infarction (MI) patients, anterior wall myocardial infarction (AWMI) patients $(30.13 \%)$ were significantly high $(p<0.05)$, in that $50 \%$ of patients received EESs, $43.18 \%$ received SESs, and $6.8 \%$ received ZESs, but in inferior wall myocardial infarction (IWMI) patients, $48.27 \%$ received SESs, $34.28 \%$ received EESs, $19.24 \%$ received ZESs, and all are considered to be significant $(p<0.05)$. In total $12.32 \%$ of anteroseptal myocardial infarction

Table 1. Baseline demographic and clinical characteristics of the patients.

\begin{tabular}{|c|c|c|c|c|c|}
\hline \multirow{2}{*}{ Characteristics } & \multirow{2}{*}{$N=146$} & G1 & G2 & G3 & \multirow{2}{*}{$p$-value } \\
\hline & & SESs $(N=63)$ & EESs $(N=53)$ & ZESs $(N=30)$ & \\
\hline Age (years) & $56.36 \pm 9.65$ & $54.29 \pm 9.14$ & $57.88 \pm 10.42$ & $57.73 \pm 8.17$ & $0.0082 * *$ \\
\hline Sex (male) & $119(81.05)$ & $54(85.71)$ & $41(77.35)$ & $24(80.00)$ & $0.0129^{*}$ \\
\hline Diabetes mellitus & $60(41.09)$ & $21(35.00)$ & $28(46.67)$ & $11(18.33)$ & $0.0458 *$ \\
\hline Hypertension & $63(43.15)$ & $22(34.92)$ & $31(49.20)$ & $10(15.87)$ & $0.0246^{*}$ \\
\hline Hypercholestremia & $13(08.09)$ & $04(30.76)$ & $04(30.76)$ & $05(38.46)$ & $0.0059 * *$ \\
\hline Smoker & $29(19.86)$ & $16(55.17)$ & $09(31.03)$ & $04(13.79)$ & $0.0897^{\mathrm{ns}}$ \\
\hline Alcoholic & $19(13.01)$ & $07(36.84)$ & $07(36.84)$ & $05(26.31)$ & $0.0109^{*}$ \\
\hline Family history of CAD & $23(15.75)$ & $12(52.17)$ & $07(30.43)$ & $04(17.39)$ & $0.0415^{*}$ \\
\hline
\end{tabular}


Table 2. Baseline cardiovascular characteristics of the patients.

\begin{tabular}{lccccc}
\hline \multirow{2}{*}{ Diagnosis } & \multirow{N}{*}{$\mathbf{N} \mathbf{1 4 6}$} & $\mathbf{G 1}$ & $\mathbf{G 2}$ & $\mathbf{G 3}$ & \multirow{2}{*}{-value } \\
\cline { 3 - 5 } & & $\mathbf{S E S s}(\boldsymbol{N}=\mathbf{6 3})$ & $\mathbf{E E S s}(\boldsymbol{N}=\mathbf{5 3})$ & ZESs $(\boldsymbol{N}=\mathbf{3 0})$ & \\
\hline Angina pectoris & $75(51.36)$ & $23(30.66)$ & $29(38.66)$ & $23(30.66)$ & $0.0064^{* *}$ \\
SVD & $26(17.80)$ & $15(57.69)$ & $05(19.23)$ & $06(23.07)$ & $0.0104^{*}$ \\
MVD & $36(26.71)$ & $23(58.97)$ & $06(15.38)$ & $09(23.07)$ & $0.0368^{*}$ \\
AWMI & $44(30.13)$ & $19(43.18)$ & $22(50.00)$ & $03(06.08)$ & $0.0370^{*}$ \\
IWMI & $29(19.86)$ & $14(48.27)$ & $05(17.24)$ & $10(34.48)$ & $0.0455^{*}$ \\
ASMI & $18(12.32)$ & $12(66.67)$ & $01(05.55)$ & $05(27.78)$ & $0.0225^{*}$ \\
\hline
\end{tabular}

All the values are expressed as $N(\%)$, where $p<0.001 * * *$ (highly significant), $p<0.01 * *$ (moderately significant), $p<0.05 *$ (significant), and $p>0.05 \mathrm{~ns}$ (non-significant).

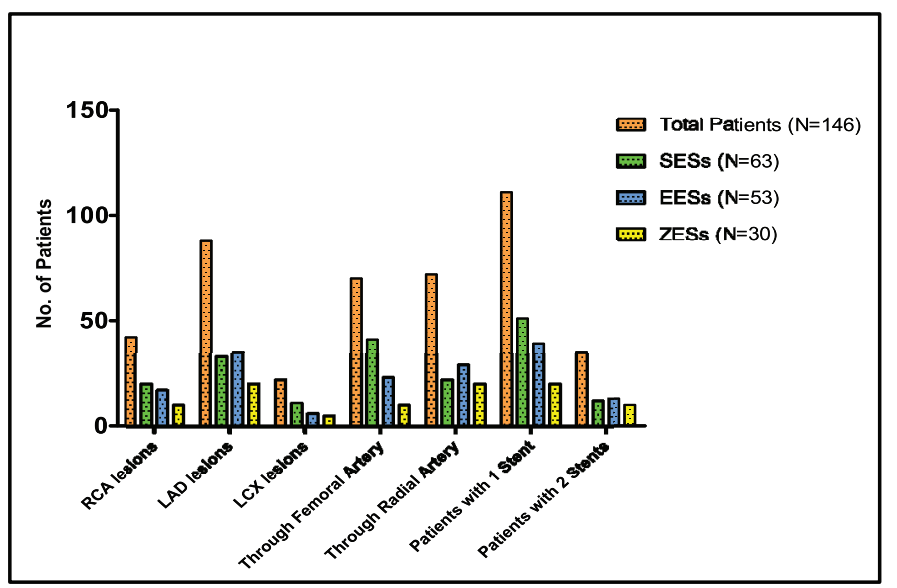

Figure 1. Angiographic and stent features.

(ASMI) patients, SESs $(66.67 \%)$ were significantly high $(p<$ $0.05)$ than EESs $(5.55 \%)$ and ZESs $(27.78 \%)$, and it is observed that in both IWMI and ASMI diagnosed patients, SESs were highly utilized than other two DESs which are all summarized in Table 2.

\section{Angiographic characteristics and stent features}

Coronary lesions were classified according to the American Heart Association and American College of Cardiology guidelines (Ryan et al., 1988). When comparing the three groups, SESs implanted patients had maximum right coronary artery (RCA) lesions (41.67\%) then EESs (35.41\%) and ZESs (20.83\%) patients before subject to angioplasty. Comparatively left anterior descending coronary artery lesions also significantly high $(p<0.05)$ in SESs (37.50\%) and EESs (39.77\%) which are similar each other, respectively, then ZESs (22.72\%). Similarly, SESs groups show $(50 \%)$ significantly high $(p<0.05)$ left circumflex artery (LCX) lesions then EESs (27.27\%) and ZESs (22.72\%), both demonstrate more or less similar LCX lesions, respectively, shown in Figure 1, these angiographic characteristics indicate that SESs group patients received maximum of all the three lesions such as RCA, LCA, and LCX lesions compared with other two groups before subject to angioplasty, stent features also state that SESs $(55.40 \%)$ were the maximum stent that placed through femoral artery, while through radial artery EESs (40.27\%) were found to be significantly high ( $p$ $<0.05$ ) based on triple vessel disease (TVD) data; patients those received one stent were maximum in SESs (45.94\%) but patients intervened with two stents was moderately significant in EESs (37.14\%) then other two DESs.

\section{Clinical outcomes during the follow-up}

The clinical follow-up of patients was conducted for 3 months once during their hospital visits or via regular phone contact at the end of 3rd, 6th, 9th, and 12th month up to 1 year after they successfully underwent angioplasty. The (mean \pm SD) value for total patients was (5.346 \pm 0.253$)$, where SESs (5.429 \pm $0.244)$, EESs (5.762 \pm 0.217$)$, and ZESs $(5.238 \pm 0.257)$ which are all found to be highly significant $(p<0.0001)$ described in Table 3 . It is observed that in this study period, $0.013 \%$ patients were died in ZESs and $0.006 \%$ in EESs and none were died in SESs group. No patients were died due to non-fatal MI but only one patient had TVR $(0.006 \%)$. The overall MACE were found to be high $(0.02 \%)$ in ZESs, EESs had $0.013 \%$ but nil in SESs group, the medication therapies used by patients of all three groups during the study period are shown in Figure 2. At the final follow-up, it is observed that $73.6 \%$ of patients were using aspirin and $39.2 \%$ were using clopidogrel but among the highest is statin about $81.6 \%$ of patients using the drug, but it was found that all these drugs were prescribed with optimal dose; therefore, these drugs have no impact on the results of this study.

\section{Suspected adverse reactions by drug eluting stents}

Minor adverse reactions include allergic reaction, nausea, vomiting etc. Major adverse reactions includes stent thrombosis, in-stent restenosis, etc.. In total $(N=146)$ patients, $0.04 \%$ was suspected with minor and $0.003 \%$ with major adverse reactions, in that SESs patients received $0.01 \%$ of minor and $0 \%$ of major suspected adverse reactions, EESs patients received $0.02 \%$ and $0.01 \%$, and in the another group ZESs patients show $0.01 \%$ and $0.002 \%$ of minor and major suspected adverse reactions, overall SESs group patients received less minor and major adverse reactions compared with EESs and ZESs which are all shown in Figure 3.

\section{DISCUSSION}

This study was designed to assess the safety and efficacy of commonly intervened first and second-generation DESs in patients with stable and unstable CAD with coronary lesions at low-to-medium risk of restenosis (large vessels, no long lesions, and no complex lesions) and in whom the use of DES is not indicated (patients presenting with STEMI). During the clinical follow-up, by comparing the overall MACE, it was observed that 
Table 3. Clinical outcomes during the follow-up.

\begin{tabular}{|c|c|c|c|c|c|}
\hline Clinical Outcomes & $N=146$ & G1 & G2 & G3 & $p$-value \\
\hline Clinical follow-up & $5.346 \pm 0.253$ & $5.429 \pm 0.244$ & $5.762 \pm 0.244$ & $5.238 \pm 0.257$ & $0.0001 * * *$ \\
\hline Patient died & $3(0.02)$ & $0(0)$ & $1(0.006)$ & $2(0.013)$ & $0.0221 *$ \\
\hline Non-fatal MI & $0(0)$ & $0(0)$ & $0(0)$ & $0(0)$ & - \\
\hline
\end{tabular}

All the values are expressed as mean $\pm \mathrm{SD}$ and $N(\%)$, where $p<0.001 * * *$ (highly significant), $p<0.01 * *$ (moderately significant), $p<0.05 *$ (significant), and $p>0.05 \mathrm{~ns}$ (non-significant).

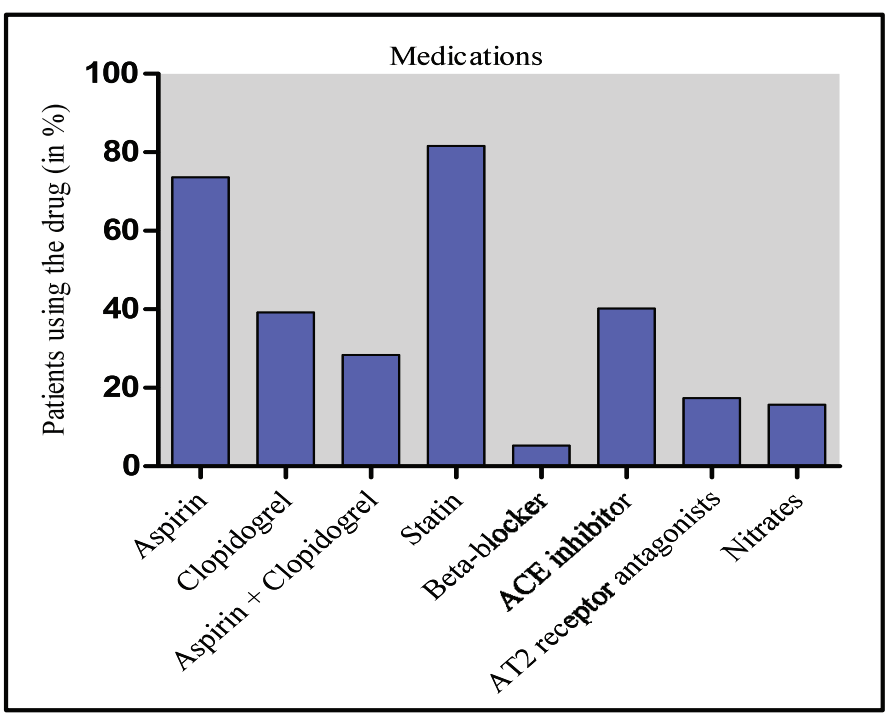

Figure 2. Medication in-use by patients during the final follow-up.

SESs had zero percentage of MACE when compared with other two DESs. The suspected adverse reactions like allergy, in-stent restenosis, etc., are also very less and only minor in SESs group. This study results indicate that SESs had comparatively high efficacy and less adverse reactions than EESs and ZESs. It was also observed that next to SESs, EESs shows better efficacy and fewer adverse reactions than ZESs.

Cardiological Society of India (CSI) is responsible for the collection and analysis of data on coronary interventions from various centers of the country, yearly data on coronary interventions in India are published periodically by the CSI; therefore, this study results will support the publication of upcoming CSI report. The prevalence of CAD and interventional centers offering PCI are increasing day by day in India like developing countries and there is an exponential need for successful diagnostic cum interventional coronary procedures and selection of best suitable DESs according to the need of the CAD patients. For this consequence, a comprehensive evaluation of safety and efficacy of commonly prescribed DESs (Table 4) is needed; therefore, this study report will also be used as a one of the sources of information for better clinical decision by the interventional cardiologists during the selection of DES for PCI.

Several landmark clinical trials demonstrated the superiority of first-generation DESs over the BMS predecessors, most of the published data demonstrated that SESs may be

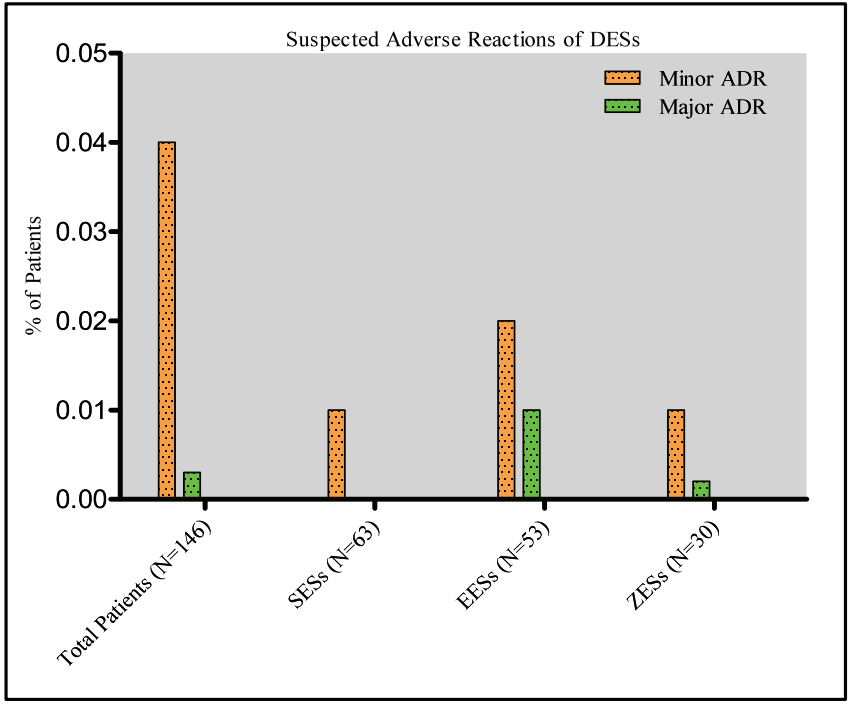

Figure 3. Suspected adverse reactions of drug eluting stents

superior to paclitaxel eluting stent (PES) based on the reductions in MACE by decreases in TLR in a 1-year follow-up period (Stephan ., 2005). On the other hand, most of the trials demonstrate that second-generation DESs with their improved properties offer significantly superior efficacy and safety profiles compared with first-generation DESs for CAD patients those receiving PCI (Kolandaivelu et al., 2011; Planer et al., 2011), but only few studies relieved that some first-generation DESs were found with same safety as second-generation DESs. Recently, a new medical terminology DDESI was discovered by the Pharmacologist Dr. Vinoth Prabhu Veeramani in CAD patients after PCI during his multi-center cross-sectional observational study which concluded that SESs were found to be more suitable and safe when compared with EESs and ZESs in CAD patients those initially considered as not suitable for PCI but prescribed with medications include aspirin, atorvastatin, and clopidogrel later recommended for PCI (Wikipedia contributors, 2019).

Early-generation DESs such as Sirolimus and Paclitaxel had stainless-steel platforms, whereas new-generation DESs release Everolimus or Zotarolimus and feature cobalt chrome or platinum chrome platforms with thinner brace thickness, more biocompatible durable polymer coatings, besides all these stents are approved by Food and Drug Administration. These new-generation stents have almost completely replaced PES from clinical practice (Stefanini et al., 2013), but not SESs 
Table 4. Characteristics of drug eluting stents studied.

\begin{tabular}{|c|c|c|c|c|c|c|c|}
\hline Stent type & Eluting drug & Brand name & Scaffold material & $\begin{array}{l}\text { Strut thickness } \\
\qquad(\mu \mathrm{m})\end{array}$ & Polymer material & $\begin{array}{c}\text { Polymer } \\
\text { thickness }(\mu \mathrm{m})\end{array}$ & Drug elution kinetics \\
\hline First generation & Sirolimus & $\begin{array}{l}\text { Cypher (Raptor \& } \\
\text { Raptorrail) }\end{array}$ & Stainless steel & 140 & PEVA, PBMA & 12.6 & $80 \%$ within the first 4 weeks \\
\hline \multirow{2}{*}{$\begin{array}{l}\text { Second } \\
\text { generation }\end{array}$} & Everolimus & $\begin{array}{l}\text { Xience (V, Prime, } \\
\text { Xpedition \& Alpine) }\end{array}$ & Cobalt-chromium & 81 & PBMA, PVDF-HFP & 7.6 & $80 \%$ within the first 4 weeks \\
\hline & Zotarolimus & $\begin{array}{l}\text { Resolute Onyx \& } \\
\text { Endeavor }\end{array}$ & Cobalt-chromium & 91 & $\begin{array}{l}\text { PBMA, PHMA, } \\
\text { PVP, PVA }\end{array}$ & 5.6 & $85 \%$ within the first 8 weeks \\
\hline
\end{tabular}

PEVA = Poly-ethylene-co-vinyl acetate, PBMA = Poly-n-butyl methacrylate, PHMA = Poly-hexyl methacrylate, PVP = Polyvinylpyrrolidone, PVA = Polyvinyl acetate PVDF-HFP = Copolymer of vinylidene fluoride and hexafluoro-propylene.

which are still manufactured and prescribed due to its stability over the biocompatibility and durability of second-generation DESs. Therefore, this study report acknowledges the noninferior efficacy and safety profile of SESs (a first-generation DES) over the EESs and ZESs (second-generation DESs) for the first time in India based on the demographical and clinical data obtained.

\section{Limitations}

There were some limitations to this present study; hence, it was a retro-prospective study relatively limited number of patients only included in this study according to the availability of patients and their records because the optical coherence tomography guidance of the intervention and angiographic followup were available only for the minority of patients. However, the main purpose of this study was to compare the safety and efficacy of commonly used DESs; therefore, the present study and its results are meaningful and despite of its limitations.

\section{CONCLUSIONS}

The present study revealed adequate efficacy and safety profile of commonly prescribed DESs in South India using medium term clinical follow-up period. Significant proportion of CAD patients with moderate cardiovascular risk those underwent PCI with DESs were included and validated in this study. Based on the results obtained, we hypothesized that SESs were found to be non-inferior to EESs and ZESs in reducing risks of TV-MI, TVR, MACE, and cardiogenic death and still show significant efficacy and safety profiles in the South Indian CAD patients during the 1-year follow-up after PCI. Our comparative subanalysis differentiates the clinical outcomes between SESs, EESs, and ZESs. These findings indicates that SESs (a first-generation DES) remain safe and effective during the 1-year clinical followup and patients with moderate cardiovascular risk still benefit from SESs with satisfactory clinical outcomes.

It was concluded that SESs were found to be more efficient when compared with EESs and ZESs according to the monitoring parameters studied in South Indian CAD population; therefore, selective usage of SESs will be advantageous and desirable in patients with moderate cardiovascular risk; hence, change in therapy or optimization may be needed for the use of EESs and ZESs although both have more biocompatibility and durability over SESs. Further study with huge population size at multinational level is obligatory to support these results for the wellbeing of CAD patients. Overall, this study explores the therapeutic benefits of SESs (a first-generation DES) over EESs and ZESs (second-generation DESs), these may have reflective economic benefits on CAD patients with moderate cardiovascular risk those selected for PCI, especially in India and other developing countries with respect to safety and efficacy.

\section{CONFLICT OF INTEREST}

All authors declare no potential conflicts of interest, including any financial, personal, patent ownership, stock ownership, consultancies, and speaker's fees or other relationships with other people or organizations within that could inappropriately influence or be perceived to influence this work.

\section{ACKNOWLEDGMENTS}

Authors are thankful to Chairman and Secretary, Vivekanandha Educational Institutions, Tiruchengode and acknowledge the Vivekanandha Medical Care Hospital, Tiruchengode, Apollo Multi-Speciality Hospital, Trichy and Sri Gokulam Hospital, Salem for providing facilities and patients' data support for this work. Moreover, we are grateful to all the interventional cardiologists who helped us and patients who are all participated in this study without any time constraint.

\section{REFERENCES}

Barton M, Gruntzig J, Husmann M, Rosch J. Balloon Angioplasty The Legacy of Andreas Gruntzig, M.D. (1939-1985). Front Cardiovasc Med, 2014; 1:1-25.

Benjamin EJ, Blaha MJ, Chiuve SE, Cushman M, Das SR, Deo R, De ferranti SD, Floyd J, Fornage M, Gillespie C, Isasi CR, Jimenez MC, Jordan LC, Judd SE, Lackland D, Lichtman JH, Lisabeth L, Liu S, Longenecker CT, Mackey RH, Matsushita K, Mozaffarian D, Mussolino ME, Nasir K, Neumar RW, Palaniappan L, Pandey DK, Thiagarajan RR, Reeves MJ, Ritchey M, Rodriguez CJ, Roth GA, Rosamond WD, Sasson C, Towfighi A, Tsao CW, Turner MB, Virani SS, Voeks JH, Willey JZ, Wilkins JT, Wu JH, Alger HM, Wong SS, Muntner P. Heart disease and stroke statistics-2017 Update: a report from the American Heart Association. Circulation, 2017; 135:e146-603.

Feinberg J, Nielsen EE, Greenhalgh J, Hounsome J, Sethi NJ, Safi S, Gluud C, Jakobsen JC. Drug-eluting stents versus bare-metal stents for acute coronary syndrome. Cochrane Database Syst Rev, 2017; 8:CD012481.

Gupta R. Burden of coronary heart disease in India. Indian Heart J, 2005; 57(6):632-8.

Kim WJ, Lee SW, Park SW, Kim YH, Yun SC, Lee JY, Park DW, Kang SJ, Lee CW, Lee JH, Choi SW, Seong IW, Lee BK, Lee NH, Cho YH, Shin WY, Lee SJ, Lee SW, Hyon MS, Bang DW, Park WJ, Kim HS, Chae JK, Lee K, Park HK, Park CB, Lee SG, Kim MK, Park KH, Choi YJ, Cheong SS, Yang TH, Jang JS, Her SH, Park SJ. Randomized comparison of everolimus-eluting stent versus sirolimus-eluting stent implantation for de novo coronary artery disease in patients with diabetes mellitus (ESSENCEDIABETES). Circulation, 2011; 124(8):886-92.

Karjalainen PP, Ylitalo A, Airaksinen JK, Nammas W. Fiveyear clinical outcome of titanium-nitride-oxide-coated bioactive stent 
implantation in a real-world population: a comparison with paclitaxeleluting stents: the PORI registry. J Interv Cardiol, 2011; 24(1):1-8.

Kolandaivelu K, Swaminathan R, Gibson WJ, Kolachalama VB, Nguyen-Ehrenreich KL, Giddings VL, Coleman L, Wong GK, Edelman ER. Stent thrombogenicity early in high-risk interventional settings is driven by stent design and deployment and protected by polymer-drug coatings. Circulation, 2011; 123(13):1400-09.

Li Y, Zheng Z, Xu B, Zhang S, Li W, Gao R, Hu S. Comparison of drug-eluting stents and coronary artery bypass surgery for the treatment of multivessel coronary disease: three-year follow-up results from a single institution. Circulation, 2009; 119(15):2040-50.

Nabel EG, Braunwald E. A tale of coronary artery disease and myocardial infarction. N Engl J Med, 2012; 366(1):54-63.

Pellegrini DO, Gomes VO, Lasevitch R, Smidt L, Azeredo MA, Ledur P, Bodanese R, Sinnott L, Moriguchi E, Caramori P. Efficacy and safety of drug-eluting stents in the real world: 8-year follow-up. Arq Bras Cardiol, 2014; 103(3):174-82.

Planer D, Smits PC, Kereiakes DJ, Kedhi E, Fahy M, Xu K, Serruys PW, Stone GW. Comparison of everolimus- and paclitaxel-eluting stents in patients with acute and stable coronary syndromes: Pooled results from the SPIRIT (a clinical evaluation of the XIENCE V everolimus eluting coronary stent system) and COMPARE (a trial of everolimus-eluting stents and paclitaxel-eluting stents for coronary revascularization in daily practice) trials. JACC Cardiovasc Interv, 2011; 4(10):1104-15.

Patel AR, Antkowiak PF, Nandalur KR, West AM, Salerno M, Arora V, Christopher J, Epstein FH, Kramer CM. Assessment of advanced coronary artery disease advantages of quantitative cardiac magnetic resonance perfusion analysis. J Am Coll Cardiol, 2010; 56(7):561-9.

Ryan TJ, Faxon DP, Gunnar RM, Kennedy JW, King 3rd SB, Loop FD, Peterson K L, Reeves T J, Williams DO, Winters Jr WL. Guidelines for percutaneous transluminal coronary angioplasty. A report of the American College of Cardiology/American Heart Association Task Force on Assessment of Diagnostic and Therapeutic Cardiovascular Procedures (Subcommittee on Percutaneous Transluminal Coronary Angioplasty). Circulation, 1988; 78(2):486-502.

Sanchis GF, Perez QC, Leischik R, Lucia A. Epidemiology of coronary heart disease and acute coronary syndrome. Ann Transl Med, 2016; 4(13):256

Stefanini GG, Holmes DR. Drug-eluting coronary-artery stents. N Engl J Med, 2013; 368:254-65.

Sidney S, Rosamond WD, Howard VJ, Luepker RV. National Forum for Heart Disease and Stroke Prevention. The "heart disease and stroke statistics-2013 update" and the need for a national cardiovascular surveillance system. Circulation, 2012; 127(1):21-3.

Stettler C, Wandel S, Allemann S, Kastrati A, Morice MC, Schomig A, Pfisterer ME, Stone GW, Leon MB, de Lezo JS, Goy JJ, Park SJ, Sabate M, Suttorp MJ, Kelbaek H, Spaulding C, Menichelli M, Vermeersch P, Dirksen MT, Cervinka P, Petronio AS, Nordmann AJ, Diem P, Meier B, Zwahlen M, Reichenbach S, Trelle S, Windecker S, Juni P. Outcomes associated with drug-eluting and are metal stents: a collaborative network meta-analysis. Lancet, 2007; 370(9591):937-48.

Stephan W, Andrea R, Franz RE, Peter J, Lorenz R, Peter W, Mario T, Michael B, David T, Christian S, Marco R, Roberto C, Gabor S, Willibald M, Thomas L, Otto MH, Matthias E, Bernhard M. Sirolimuseluting and paclitaxel-eluting stents for coronary revascularization. N Engl J Med, 2005; 353(7):653-62

Trevor S, Benjamin H, Daniel R, Michael F, Yong XC, Edward RO Brien. The evolution of coronary stents: a brief review. Canadian J Cardiol, 2014; 30:35-45.

Veeramani VP. New concern: Drug-Drug eluting stent interaction (DDESI) between drugs prescribed and Drug eluting stents (DESs) after percutaneous coronary intervention (PCI) in coronary artery disease (CAD) patients: a multicenter cross-sectional observational study. J Pharm Res Int $2019 ; 25(1): 1-10$

Wikipedia Contributors. 2019. "Drug-eluting stent," Wikipedia, the free Encyclopedia. Available via https://en.wikipedia.org/w/index php?title=Drug-eluting_stent\&oldid $=881342865$ (Accessed 5 February 2019).

World Health Organization. 2017. Cardiovascular diseases; fact sheet \#317. Available via http://www.who.int/news-room/fact-sheets/detail/ cardiovascular-diseases-(cvds) (Accessed 20 July 2018).

How to cite this article:

Veeramani VP, Selvam SP, Hamdan AM. Comparative clinical evaluation of safety and efficacy of commonly used drug-eluting stents in coronary artery disease patients after angioplasty in South India: A retro-prospective multi-center study. J Appl Pharm Sci, 2019; 9(03):059-065. 